عدد خاص بالورقات العلمية المقدمة للمؤتم الدولي الثاني للتعليم في ليبيا، مصراتة، ليبيا، مارس 2019

\title{
الصعوبات التى تواجه تطبيق ضمان جودة التعليم الجامعي الخاص
}

\section{( دراسة ميدانية)}

د. محمد عاشور الشريف

جامعة طرابلس - كلية التربية

$$
\begin{aligned}
& \text { أ.د. مصطفى عبد العظيم الطبيب } 1 \\
& \text { جامعة طرابلس - كلية التربية }
\end{aligned}
$$

ملخص الدراسة

$$
\text { على الصعوبات الإدارية التنظيمية على المستوى المحلى (مستوى المؤسسة). }
$$

وتكمن أهمية الدراسة في كوها تركيز على موضوع الصعوبات التي تواجه تطبيق نظام الجودة، وتساهم في مساعدة المسؤولين ومتخذي القرار على تطوير العملية التعليمية. وتتحدد مشكلة الدراسة فن الإجابة عن التساؤل التالي: ما هي الصعوبات القيادية، والتنظيمية التى تواجه تطبيق نظام جودة التعليم الجامعي الخاص؟. وتم استخدام المنهج الوصفي التحليلي لتحقيق أهداف الدراسة، وتكونت عينة الدراسة من (40) أستاذا كُلِّفُوا برئاسة إدارات الجودة بخمس جامعات خاصة بمدينة طرابلس. واعتمد الباحثان في جمع البيانات على استمارة الاستبيان التي صممتها رقاد (2014)، وتتكون من محورين، وبعد عرضها على المحكّمين تم استبعاد بعض فقراتا، فأصبحت (34) فقرة. ولمعالجة البيانات تم استخدام المتوسط الحسابي المرجح. وتوصلت الدراسة إلى النتائج التالية: 1.ترى عينة الدراسة أن هناك العديد من الصعوبات الإدارية (القيادية) التى تواجه تطبيق نظام الجودة في التعليم الجامعي الخاص. 2. هناك قصور مؤسساتي يتعلق بجانب التخطيط من حيث عدم وضوح الأهداف وقابليتها للقياس، وغير ذلك. 3. هناك قصور واضح في بعض جوانب التنظيم كبعد إداري مؤسساتي. 4. هناك قصور واضح في بعض جوانب التوجيه كبعد إداري تنظيمي مؤسساتي. وأوصت الدراسة بما يلى: 1. وضع ضمان الجودة بالجامعات الخاصة على قائمة أولويات الدولة. 2. التعاون بين الجامعات الحكومية والجامعات الخاصة لتبادل الأفكار والخبرات بما يحقق اهداف ضمان الجودة. الكلمات المفتاحية: الجودة، التعليم الجامعي الخاص، ضمان الجودة 


\section{Abstract}

This study aims at the recognition to the administrative difficulties encounter the application of assurance of quality system of the higher private education. It also, aims at the recognition to the administrative organizational difficulties and on the local level.( the educational institution).

The importance of this study can be described in the following:

1.The study concentrates on the difficulties which face applying quality assurance system in higher private education institutions.

2. The present study contributes in assisting officials and decision makers in developing the educational process.

The study problem determined in finding an answer to the following question:

What leadership and organizational difficulties face applying quality assurance system in higher private education?

The study sample consists of (40) staff members who are in charge of quality departments and sections at five private universities. In order to achieve study objectives, the analytical descriptive method was used.

In the collection of data related to the study, the researchers depended on a questionnaire designed by Ragad (2014) as a mean for data collection. It consists of two parts. The questionnaire was revised by two experts and the researchers decided to use only (34) items. Dealing with study sample indicated that there were many administrative leadership difficulties encounter applying quality system in the higher private education. The study results showed that there was institutional deficiency related to planning; the objectives weren't clear and cannot be measured etc. The study also indicated that there was clear deficiency on the organizational level which considered as an institutional administrative dimension. Another deficiency on the guidance level was also found by the study.

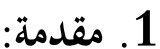

يعد التعليم العالي من الركائز الأساسية لبناء الدولة الحديثة، باعتباره أداة للتنمية البشرية التي بدورها تسهم في

ارتقاء المجتمع بأسره، لذا أصبح من الضرورة بمكان أن يشهد التعليم العالي الخاص اهتماماً دولياً من حيث معايير ضمان الجودة والاعتماد الأكاديمي، وذلك من خلال وضع الاستراتيجيات المناسبة للتكيف مع التطورات التي يشهدها عصرنا

وقد أشار تقرير اللجنة الدولية لليونسكو حول التعليم في القرن الحادي والعشرون (ويشار إليها غالباً بلجنة ديلرز The Delors Commission في كل مكان، حتى في الدول التي ينخرط فيها المتعلمون في المراحل الدنيا من التعليم (Delors, 1996:120). 
عدد خاص بالورقات العلمية المقدمة للمؤتم الدولي الثاني للتعليم في ليبيا، مصراتة، ليبيا، مارس 2019

ويشير فردكسن Ulf Fredriksson (2004) إنا أن الجودة قد أصبحت منذ ثمانينّات القرن العشرين مفهوما مهما في النقاش التعليمي، فالكل يريد تحسين الجودة في التعليم، ومن المناسب أن نتساءل لماذا أصبحت الجودة محل اهتمام عدد كبير في النقاشات التعليمية؟ ويوجد للإجابة عن هذا التساؤل ثلاثة تفسيرات: الأول: أن التعليم في العقود الأخيرة كان أقل جودة عما كان عليه. الثاني: هو التعبير عن القلق المتزايد حول التعليم، جودة التعليم، والطريقة المثلى لصرف الأموال عليه. الثالث: التركيز المتزايد على التعليم هو جزء من عملية بناء القطاع العام، وخفض الإنفاق العام، وتقديم حلول خاصة (Fredriksson, 2004:5). وقد شهد التعليم العلي الخاص في ليبيا إقبالا كبيرا بشكل غير مسبوق من قبل الطلاب الحاصلين على شهادة إتمام المرحلة الثانوية العامة، غير أن ذلك الطلب المتزايد جاء على حساب جودته، وذلك لغياب آليات التخطيط والتنظيم والتوجيه والرقابة، لأنه جاء نتيجة لأفكار وليدة لحظتها، ومن غير تفكير سابق. وفن هذا الصدد يشير تقرير عن واقع التعليم العالي في ليبيا، صدر عن المنظمة الليبية للسياسات والاستراتيجيات

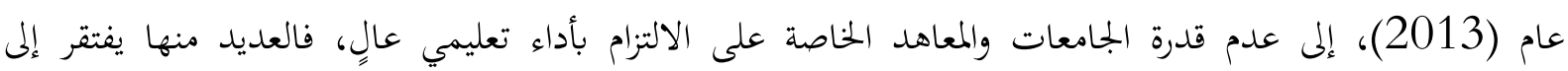
الاعتماد من قبل إدارة ضمان الجودة بمؤسسات التعليم العالي، وبالتالي فهي لا تلتزم بععايير الجودة المطلوبة (المنظمة الليبية

$$
\text { للسياسات والاستراتيجيات، 2013: 10 10). }
$$

ومن هنا أصبح كثيرٌ من تلك الجامعات والمعاهد الخاصة ملاذاً للطلاب الراسبين، أو الذين لا تنطبق عليهم معايير

$$
\text { القبول في الجامعات الليبية العامة. }
$$

وعلئ الرغم من كثرة الجامعات الخاصة فإها تفتقر إلى معايير ضمان الجودة من وجهة نظر الباحِتَّين وخبرتما، من خلال قيامهما بالتدريس في بعض الجامعات، الأمر الذى يستوجب القيام بالعديد من الدراسات حول ضمان جودة التعليم الخاص، ووضع الخطط اللازمة؛ حتى يجقق أهداف العملية التعليمية التي أنشئ من أجلها. وتأسيسا على ما تقدم تزايد الاهتمام بتحقيق ضمان الجودة في مؤسسات التعليم العالي في الجامعات الليبية الخاصة، حتى تصل إلى معايير الجودة العالمية، إلا أن هذه المؤسسات لا تزال تعاني من انخفاض معايير الجودة الأكاديمية، وعدم قدرةا على توفير المخرجات النوعية التي يتطلبها سوق العمل اللبيي، وعدم قدرقا على منافسة مؤسسات التعليم العالي العام، علن الرغم من قلة التَّمويل للأخير. وبناءً على ذلك رأى الباحثان القيام مهذه الدراسة حول الصعوبات التي تواجه التعليم الجامعي الخاص. 
تتحدد مشكلة الدراسة الحالية من خلال الإجابة عن التساؤل الرئيسي التالي: ما الصعوبات التي تواجه تطبيق نظام ضمان الجودة بمؤسسات التعليم الجامعي الخاص؟ ويتفرع عن هذا التساؤل التساؤلات الفرعية التالية:

1. ما الصعوبات الإدارية ( القيادية) التي تواجه تطبيق نظام جودة التعليم الجامعي الخاص ؟ 2. ما الصعوبات الإدارية والتنظيميّة على المستوى المحلى (مستوى المؤسسة)؟ ويندرج تحت هذا التساؤل التساؤلات الفرعية التالية:

2 أ. ما الصعوبات الإدارية والتنظيميّة على المستوى المحلى (مستوى المؤسسة) الخاصة بالتخطيط؟ 2 ب. ما الصعوبات الإدارية والتنظيمية على المستوى المحلى (مستوى المؤسسة) الخاصة بالتنظيم؟ 2 ج. ما الصعوبات الإدارية والتنظيمية على المستوى المحلى (مستوى المؤسسة) الخاصة بالتوجيه؟ 2 د. ما الصعوبات الإدارية والتنظيمية على المستوى المحلى (مستوى المؤسسة) الخاصة بالرقابة؟

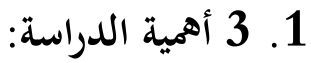

تكمن أهمية الدراسة في النقاط التالية: 1. التركيز على موضوع الصعوبات التي تواجه تطبيق نظام الجودة في مؤسسات التعلم العالي الخاص، وهذا الموضوع من الأهميّة بمكان كبير. 2. الإسهام في مساعدة المسؤولين ومتخذي القرار على تطوير العملية التعليمية في مؤسسات التعليم الجامعي الخاص، حيث إن بعضهم ما يزال غير مدرك لأهمية التعليم الخاص، الذى من شأنه تخفيف العبء عن التعليم الحكومي. 3. فتح المجال لدراسات لاحقة تهدف إلى ضمان جودة التعليم الجامعي الخاص. 1. 4 أهداف الدراسة:

$$
\text { تمدف الدراسة إلى تحقيق الآتي: }
$$

1. التعرف على الصعوبات الإدارية ( القيادية) التي تواجه تطبيق نظام جودة التعليم الجامعي الخاص. 2. التعرف على الصعوبات الإدارية والتنظيمية على المستوى المحلى (مستوى المؤسسة)، والمتمثلة في: أ. التعرف على الصعوبات الإدارية والتنظيمية على المستوى المحلى (مستوى المؤسسة) الخاصة بالتخطيط. ب. التعرف على الصعوبات الإدارية والتنظيمية على المستوى المحلى (مستوى المؤسسة) الخاصة بالتنظيم. 
ج. التعرف على الصعوبات الإدارية والتنظيمية على المستوى المحلى (مستوى المؤسسة) الخاصة بالتوجيه. د. التعرف على الصعوبات الإدارية والتنظيمية على المستوى المحلى (مستوى المؤسسة) الخناصة بالرقابة.

1 1

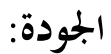

تعرف الجودة بأفا "مقدرة بجموعة خصائص ومميزات المنتج التعليمي على تلبية متطلبات المتعلم (الطالب)، وسوق العمل، والمجتمع، وكافة الجهات الداخلية والخارجية المنتفعة". (يحياوى، وآخرون، 2012: 450).

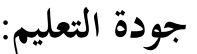

يعرف هاي وآخرون (Hoy et al (2000) جودة التعليم بأها" تقييم العملية التعليمية التي تعزز الحاجة إلى تحقيق وتطوير قدرات الطلاب، وفى ذات الوقت معايير المحاسبة التي يقوم بها المتعلمون الذين يقومون بالدفع من أجل الدراسة والتعليم" (Hoy et al, 2000). ويرى أدمز (1993) Adams أن جودة التعليم تتضمن مظهرين، هما: المظهر الأول : يتمثل في جودة النظام التعليمي بصفته وحدة واحدة، ويتضمن المدرسة أو المؤسسة التعليمية، والتدريس، والبيئة التعليمية، والسياسات التعليمية. المظهر الثاني: ما يوفره النظام التعليمي للطلاب أو المتعلمين، ويتضمن جودة التدريس، أو جودة المنهج الدراسي ، أو جودة العملية التعليمية (Adams, 1993).

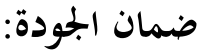

يعرفها بورثمان وآخرون Portman, et al بأها: "المستوى الذى تستطيع عنده مجموعة من المواصفات إنجاز مجموعة من الأهداف المحددة مسبقاً، ممثلة في التوجيه العام، والأهداف الاستراتيجية، أو مجموعة الأهداف المعرفية، والمهارات المرغوب في تحقيقها" ( نقلاً عن: قدومى، 2005: 47). التعليم الجامعي الخاص: يعرف الباحثان التعليم الجامعي الخاص بأنه: التعليم الذى لا يدار بواسطة الدولة، ويعتمد على التمويل الذاتي، وما يتحصل عليه من مساعدات مالية من جهات عامة، فضلاً ما يتحصل عليه من الطلاب؛ نظير الدراسة بتلك الجامعة.

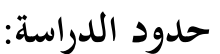

1. الحدود المكانية: مؤسسات التعليم الجامعي الخاص بمدينة طرابلس.

$$
\text { 2. الحدود الزمانية: شهر فبراير 2109م. }
$$


3. الحدود البشرية: مديرو مكاتب الجودة بالجامعات، ومنسقو مكاتب الجودة بالأقسام.

الإطار النظري للدراسة:

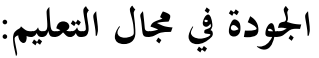

ظهر مفهوم الجودة QUALITY في ثمانينات القرن الماضي في الولايات المتحدة الأمريكية مع ارتفاع وتيرة التنافس الاقتصادي العالمي، وغزو الصناعة اليابانية للأسواق العالمية. فالجودة مفهوم اقتصادي في الأساس، يرتبط بالإنتاجية و المردودية، وانتقل إلى مجال التعليم على اعتبار أن المؤسسة التعليمية هي مؤسسة لإنتاج الكفاءات والخبرات، القادرة على الابتكار و الإبداع اللذين بدوفما لا يمكن للمجال الصناعي أن يتطور، و لا للإنتاج أن يتحسن. وترى عبلة وآخرون (2012) أن الاهتمام كان منصباً على المجال الاقتصادي والصناعي بالدرجة الأولى، ويرى بعض المتخصصين في مجال الجودة أن الجودة ومعاييرها تعرف بالثورة الثالثة بعد الثورة الصناعية والثورة التقنية ( عبلة محمد؛ وآخرون، 2012: 477).

وينظر كل مختص للجودة من مجال تخصصه، وهنا سيتم التركيز على الجودة في مجال التعليم، حيث تعددت تعريفات الجودة التعليمية، ونذكر منها ما يلى: قامت المنظمة العالمية "اليونيسيف" بتبني جودة التعليم وفقاً للتعريف الذي وضعه البروفيسور والخبير الأكاديمي العالمي بريهان (1993) لجودة التعليم، والذي صاغه بأهفا عملية التركيز على أساليب التعلّم والتعليم الفعّالة التي تدعم باستمرار قدرات المتعلّمين ومواهبهم المتنوّعة؛ لاكتساب المعرفة اللازمة والمهارات العمليّة، والسلوك التطبيقي الناتج عن منظومة فكريّة متطوّرة وملائمة مع احتياجات العصر وتحديّاته ودعم احتياجات المتعلمين؛ بحيث تخرج أجيالاً متعلّمة قادرة على اتخاذ القرار ومساعدة أنفسهم وغيرهم على حلّ المشاكل، وإيجاد الحلول المبتكرة للقضايا الشائكة، مع توفرّ بيئةٍ آمنة للتعليم والإبداع والصحة والتفاعل الإيجابي بين الشرائح التعليميّة المختلفة والمجتمع المحيط . https://mawdoo3.com/\%D8\%, in date. 28/2/2019)

ويرى سلامة (2005) أن الجودة في التعليم العالي تعنى التميز على اعتبار أن مؤسسة التعليم العالي مؤسسة لها ما يميزها، وذات مستوى عالٍ وطبيعة خاصة، وتقوم على فكرة التميز في التعليم العالي بالتركيز على مدخلات ومخرجات

$$
\begin{aligned}
& \text { النظام التعليمي ( نقلاً عن: رقاد، } 2014 \text { : 50) } \\
& \text { أهداف نظام الجودة في التعليم العالى: } \\
& \text { يرى مارتن وستيلا أن أهداف نظام ضمان الجودة في مؤسسات التعليم العالي هي: }
\end{aligned}
$$




\section{عدد خاص بالورقات العلمية المقدمة للمؤتم الدولي الثاني للتعليم في ليبيا، مصراتة، ليبيا، مارس 2019}

1. الرقابة على الجودة، إذ إن ازدياد عدد مؤسسات التعليم العالي الخاصة أدى إلى ضرورة متابعة الحكومة لمستوى الجودة بهذه المؤسسات بشكل جديّ، للتأكد من أن مخرجات التعليم العالي تتناسب مع احتياجات سوق

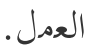

2. الشفافية، لأنه من الضروري التأكد من أن كل فرد يتحمل الدسؤولية عن تحقيق الجودة في العمليات التى يعتبر مسؤولاً عنها، إذ يجب أن يؤدى كل فرد مهامه في ضوء برامج التدريب والإجراءات التي تم تحديدها بواسطة نظام

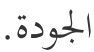
3. تحسدين الدمارسات الحالية ، وذلك من خلال إجراء التقيدم الذاتي لتزويد صانعي القرار بالتغذية الراجعة؛ لتساءدهم على وضع الاستراتيجيات والخطط، واتخاذ الإجراءات اللازمة لـصحيح الأخطاء، والعمل على تحقيق أداء

$$
\text { أفضل (نقلاً عن: رقاد، 2014: 76- 78). }
$$

أما فيما يتعلق بالأبعاد الخاصة بجودة التعليم فإن منظمة اليونسيف (2000) تؤكد بشدة على الأبعاد المرغوبة في الجودة، التي تضمنتها ورقة العمل بداكار فريم وورك (Dakar Framework)، وتضمنت خمسة أبعاد، وهى: in: Jain and N. Prasad, المتعلمون، البيئة التعليمية، المحتوى التعليمي، العمليات التعليمية، والمخرجات

\section{التعليم الجحامعي الخخاص: - n}

يعد التعليم الجامعي الخاص بتربة رائدة وجديدة يشهدها النظام التعليمي في ليبيا، وهى تجربة لازالت في مرحلة التطوير والتحسين، وعلى الرغم من وجود العديد من الجامعات الخاصة فإن المعتمدة منها لا يتعدى، وفقاً للتقرير الصادر عام (2013) من مركز ضمان الجود، (6) جامعات، نذكر منها على سبيل المثال لا الحصر: جامعة الرفاق بطرابلس، والجامعة الليبية للعلوم الطبية ببنغازي، وجامعة إفريقيا المتحدة الأهلية بالزاوية، وجامعة طرابلس الأهلية، وكلية صقر للحاسبات ببنغازي، والجامعة الليبة للعلوم الإنسانية والتطبيقية بطرابلس، إضافة إلى جامعة الحاضرة بطرابلس، وجامعة التحدي للعلوم الطبية، وهاتان الجامعتان الأخيرتان تحصلتا على اعتمادٍ مؤسسيّ فقط.

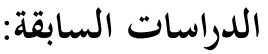

$$
\text { يعرض الباحثان بعض الدراسات السابقة التي تناولت ضمان الجودة: }
$$

- دراسة بدرخان؛ و الشوا (2012) بعنوان: " المعوقات التي تعترض تطبيق معايير النوعية وضمان الجودة في

الجامعات الأردنية من وجهة نظر أعضاء الهيئة التدريسية".

تمدف الدراسة إلى التعرف على الصعوبات التي تواجه تطبيق معايير ضمان الجودة في الجامعات الأردنية من وجهة نظر أعضاء هيئة التدريس، وتكونت عينة الدراسة من (274) عضو هيئة تدريس، منهم (134) عضو هيئة 


\section{عدد خاص بالورقات العلمية المقدمة للمؤتمر الدولي الثاني للتعليم في ليبيا، مصراتة، ليبيا، مارس 2019}

تدريس من جامعة عمان العربية، و(140) من الجامعة الأردنية، وأظهرت نتائج الدراسة أن أهم المعوقات التي تعترض تطبيق النوعية وضمان الجودة في الجامعات الأردنية من وجهة نظر أعضاء هيئة التدريس تتعلق بالبحث العلمي، كما أظهرت نتائج الدراسة عدم وجود فروق ذات دلالة إحصائية في المعوقات التي تعترض النوعية وضمان الجودة تعزى إلى متغير الجامعة والكلية. - دراسة السرحان (2012) بعنوان: " أثر تطبيق معايير الجودة والاعتماد الأكاديمي على تسويق مخرجات التعليم في الجامعات السعودية".

تمدف الدراسة إلى التعرف على أثر تطبيقات معايير الجودة والاعتماد الأكاديمي على تسويق مخرجات التعليم في الجامعات السعودية، وقد تم اختيار عينة الدراسة التي تكونت من (82) من العاملين في مجال الجودة والاعتماد الأكاديمي، والموظفين في الجامعات السعودية، وتوصلت الدراسة إلى عدة نتائج منها: وجود علاقة ارتباطية موجبة بين تركيز الإدارة العليا على الرسالة والأهداف وتسويق مخرجات التعليم في السعودية، وأيضاً وجود علاقة موجبة بين تركيز الجامعات السعودية على الثقافة التنظيمية كأحد عناصر الجودة وبين تسويق مخرجات التعليم في السعودية، ووجود علاقة موجبة بين تركيز الجامعات السعودية على العاملين وبين تسويق مخرجات التعليم في السعودية، وكذلك وجود علاقة ارتباطية موجبة بين تركيز الجامعات السعودية على المسؤولية الاجتماعية وبين مخرجات تسويق التعليم. - دراسة الرفاعي وآخرين (2012)، بعنوان: " تحديد معوقات إدارة الجودة الشاملة في أقسام المحاسبة في الجامعات الأردنية".

تمدف الدراسة إلى التعرف على المشاكل التي تواجه أعضاء هيئة التدريس في قسم المحاسبة، وتحول دون تحقيق إدارة الجودة الشاملة في الجامعات الحكومية الأردنية، وتكونت عينة الدراسة من (72) عضو هيئة تدريس في أقسام المحاسبة في كل من جامعة البلقاء التطبيقية، وكلية عمان الجامعية للعلوم المالية والمصرفية، وتوصلت الدراسة إلى عدة نتائج منها: عدم وجود تعاون بين الجامعة وسوق العمل، وضعف الدعم المالي المقدم للأبحاث العلمية، وعدم قناعة بعض القيادات الأكاديمية بأهمية تطبيق نظام الجودة. - دراسة بلبية محمد (2015) بعنوان: " تحديد معايير ضمان الجودة وتأثيرها على الاعتماد الأكاديمي

$$
\text { - مجمؤسسات التعليم العالي" . }
$$

1. التعرف على معايير الجودة والاعتماد الأكاديمي في مؤسسات التعليم العالي. 2. تحديد أهم الصعوبات التي تحول دون تطبيق معايير الجودة في مؤسسات التعليم العالي. 


\section{عدد خاص بالورقات العلمية المقدمة للمؤتر الدولي الثاني للتعليم في ليبيا، مصراتة، ليبيا، مارس 2019}

وتكونت عينة الدراسة من (171) أستاذا، منهم (74) أستاذا، (97) أستاذة من كلية العلوم الاقتصادية

والتجارية بجامعة أبوبكر بلقائد (تلمسان) للعام الجامعي 2015، تم استخدام المنهج الوصفي، وتوصلت الدراسة إلى النتائج التالية:

1. أكدت عينة الدراسة على أن محور الرؤية والرسالة والتخطيط تتوفر على معايير الجودة. 2. يتضح من النتائج أن عينة الدراسة غير راضية عن البحث العلمي على مستوى الكلية والجامعة. 3. أن محور البرامج التعليمية لم يصل للحد المطلوب.

4. تبين من نتائج الدراسة أن محور إدارة الجودة لم يصل للحد المطلوب، حيث ترى عينة الدراسة أن هناك تقصير

$$
\text { من رؤساء إدارات الجودة. }
$$

- دراسة بن حسين (2016) بعنوان: " تقييم فعالية ضمان الجودة في المساهمة في بناء وتطوير نظام ضمان

$$
\text { جودة التعليم العالي في الجزائر". }
$$

تمدف الدراسة إلى التعرف على التوجهات الحديثة لأنظمة التعليم العالي في العالم ، كما تمدف أيضاً إلى التعرف على واقع التعليم العالي في الجزائر في ضوء التوجهات الجديدة، والتعرف على فعالية خلايا ضمان الجودة في المساهمة في بناء وتطوير ضمان جودة التعليم العالي في الجزائر. وتكونت عينة الدراسة من (22) مسؤولا وعضوا في وحدة ضمان الجودة بثلاث جامعات من الشرق الجزائري، وقد استخدم الباحث المنهج الوصفي التحليلي، وتوصلت الدراسة إلى النتائج التالية: 1. إن خلايا ضمان الجودة لا تسهم بالقدر الكافي في التقييم الداخلي لبرامج العمل المؤسساتي. 2. إن خلايا ضمان الجودة بعيدة عن درجة الفاعلية المطلوبة في إعلام الفاعلين والمهتمين بالتعليم العالي حول إجراءات ضمان الجودة التي تقوم بها والفائدة التي يمكن تحقيقها من هذه الإجراءات. 3. إن خلايا ضمان الجودة لا تؤدى وظيفة الاتصال بالفاعلين على المستويين الداخلي والخارجي بالشكل المطلوب. - دراسة رقاد؛ والعكيكيزة (2016) بعنوان: "معوقات تطبيق نظام ضمان الجودة في مؤسسات التعليم العالي الجزائرية، دراسة حالة الجامعات العمومية الجزائرية. تدف هذه الدراسة إلى التعرف على المعوقات التي تحول دون تطبيق نظام ضمان الجودة في الجامعات العمومية الجزائرية من وجهة نظر مسؤولى وحدات ضمان الجودة. ولتحقيق هدف الدراسة تم تطبيق الاستبانة كأداة قياس بعد التحقق من الخصائص السيكومترية لها. وقد توصلت الدراسة إلى تحديد جملة من المعوقات ،كان أهما: عدم وضوح سياسة تطبيق نظام ضمان الجودة، وعدم حرص وزارة التعليم العالي 


\section{عدد خاص بالورقات العلمية المقدمة للمؤتم الدولي الثاني للتعليم في ليبيا، مصراتة، ليبيا، مارس 2019}

والبحث العلمي على توثيقها، وعدم حرص الإدارة العليا للجامعة على إدماج خلية ضمان الجودة في الهيكل التنظيمي للجامعة، وعدم منح الصلاحيات الكافية لمسؤول وحدة ضمان الجودة لأداء مهامه، وعدم حرص الإدارة العليا للجامعة على متابعة مدى التقدم في عملية تطبيق نظام ضمان الجودة والوقوف على ذلك، والحوف من التقييم، وبذل جهد إضافي إلى جانب فقدان الاستقلالية والنفوذ. - دراسة زين السمدى وآخرين (2017) بعنوان: " مدى تطبيق معايير ضمان الجودة والاعتماد الأكاديمي فن جامعة الأندلس". تمدف الدراسة إلى معرفة مدى تطبيق معايير ضمان الجودة والاعتماد الأكاديمي في جامعة الأندلس، وتكونت عينة الدراسة من (66) إداريًّ وأكاديميًا، واستخدم المنهج الوصفي التحليلي في هذه الدراسة، وتوصلت الدراسة إلى أنه لا توجد فروق دالة إحصائياً بين استجابات أفراد عينة الدراسة حول مدى تطبيق المعايير تعزى لمتغيرات، ( الجنس، المسمى الوظيفي، نوع الكلية، المؤهل العلمي، سنوات الخبرة). - دراسة النقرى، والطروانة (2018) بعنوان: "درجة تحقيق الجامعات الأردنية لمعايير ضمان الجودة من وجهة

$$
\text { نظر عمداء الكليات ورؤساء الأقسام الأكاديمية فيها". }
$$

هدفت الدراسة إلى التعرف على درجة تحقيق الجامعات الأردزية لمعايير ضمان الجودة من وجهة زظر عدداء الكليات ورؤساء الأقسام الأكاديمية فيها. وقد تكوزت عينة الدارسة من(220) عميدا ورئيس قسم بواقع (59) عميدا، (161) رئيس قسم، تم اخزيارهم بطريقة قصدية من ثلاث جامعات حكومية، وثلاث جامعات خاصة في الأردن، واستخدم منهج البحث الدسحي، كما استخدمت الاسدبانة أداة لجمع البيانات بعد أن تم التأكد من صدقها وثباتها ـوأظهرت زتائج الدارسة أن درجة تحقيق الجامعات الأردزية لمعايير ضمان الجودة من وجهة نظر عمداء الكليات ورؤساء الأقسام الأكاديمية فيها مرتفعة ، وأن هناك فروقا ذات دلالة إحصائية عند مستوى (0.05) في تقديرات عمداء الكليات ورؤساء الأقسام الأكاديمية لدرجة تحقيق الجامعات الأردزية لمعايير ضمان الجودة وفقاً لمتغير الدسمى الوظيفى.

\section{20 (إجراءات الدراسة: 2. 2 1 2 منهج الدراسة:}

اعتمدت الدراسة الحالية على المنهج الوصفي التحليلي في تحقيق أهدافها، حيث تم في الجانب النظري مراجعة التراث الأدبي للدراسة المتعلق بضمان جودة التعليم العالي بشكل عام، والصعوبات التي تعترضه في الوطن العربي، وذلك من خلال الدراسات السابقة، كما تم في الجانب الميداني الوقوف على أهم الصعوبات 
عدد خاص بالورقات العلمية المقدمة للمؤتم الدولي الثاني للتعليم في ليبيا، مصراتة، ليبيا، مارس 2019 لئل

التي تواجه تطبيق ضمان جودة التعليم الجامعي الخاص من وجهة نظر رؤساء ومنسقي وحدات الجودة

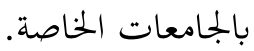

2

تكونت عينة الدراسة من (40 ) أستاذا، مكلفين بإدارة ضمان الجودة بالجامعات الخاصة، والأقسام العلمية، وتم اختيارهم من (5) جامعات خاصة، هى: جامعة الرفاق، جامعة طرابلس، جامعة إفريقيا، جامعة الحاضرة، الجامعة الليبية بتاجوراء.

2. - 2 2 3 بعد الاطلاع على عدد من المقاييس والاستبانات المستخدمة في الدراسات السابقة، قرر الباحثان الاعتماد على استمارة الاستبيان التي صممتها الباحثة صليحة رقاد (2014) لجمع البيانات الخاصة بالدراسة الحالية، وذلك لشمولية بنود هذه الاستمارة، حيث تتكون الاستمارة الأصلية المصممة من الباحثة من (5) محاور، اعتمد الباحثان على محور واحد من الخمسة محاور، وهو المحور الذى يتعلق بالدراسة الحالية، ويتكون من (41) فقرة، أبقى الباحثان على (34) فقرة منه بعد عرض الاستمارة على عدد من المتخصصين في التربية وعلم النفس، حيث رأى الأساتذة أن بعض الفقرات لا تخدم الدراسة الحالية، وبعضها يغلب عليه التكرار، وبذلك تم حذف (7) فقرات، وتتم الإجابة على الاستمارة من خلال (5) بدائل، وهى: (موافق بشدة، موافق، محايد، غير موافق، غير موافق بشدة)، وأعطيت لهذه البدائل الأوزان التالية: (5، 4، 3، 2، 1)، ويعالج هذا المحور الصعوبات التي تواجه تطبيق نظام الجودة في مؤسسات التعليم العالي، وينقسم إلى

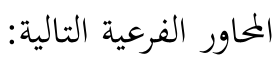
1. المحور الأول: يتعلق بالجانب القيادي على المستوى المركزي (الوزارة)، ويتكون من (7) فقرات. 2. المحور الثاني: يتعلق بالجانب الإداري والتنظيمي على المستوى المحلى (المؤسسة)، ويتكون من أبعاد فرعية، أ. البعد الخاص بالتخطيط ويتكون من (7) فقرات. ب. البعد الخاص بالتنظيم ويتكون من (9) فقرات. ج. البعد الخاص بالتوجيه ويتكون من (8) فقرات. د. البعد الخاص بالرقابة ويتكون من (3) فقرات. المعالجة الإحصائية للبيانات: 
استخدم الباحثان المتوسط الحسابي المرجح (الموزون) Weighted Arithmetic Mean ، وبما أن المتغير الذى يعبر عن الخيارات أو البدائل (موافق بشدة، موافق، محايد، غير موافق، غير موافق على الإطلاق) ، والأرقام التي تدخل في البرنامج تعبر عن الأوزان Weights ، وهى بالترتيب (5، 4، 3، 2، 1)، ويتم حساب المتوسط المرجح بحساب مدى الفترة أولاً ، وهى في هذه الدراسة حاصل طرح أكبر وزن من أصغر وزن، وهى (5-1=4)، ومن ثمّ قسمة المدى على أكبر وزن (4 ٪5 = 0.80)، حيث (4) تمثل عدد المسافات (من 1 إلى 2) مسافة أولى، (من 2 إلى 3) مسافة ثانية، (من 3 إلى 4) مسافة ثالثة، (من 4 إلى 5) مسافة رابعة ( الفرا، 1430 :25). لذا يصبح التوزيع على النحو التالي: جدول (1) يبين المتوسطات الحسابية المرجحة والأوزان المئوية

\begin{tabular}{|c|c|c|c|}
\hline درجة الموافقة & الوزن المئوي & المستوى & المتوسط المرجح \\
\hline ضعيفة جدا & 0.20 - أقل من 0.36 & غير موافق على الإطلاق & 1.79 \\
\hline ضعيفة & 0.36- أقل من 0.52 & غير موافق & $2.59-1.80$ \\
\hline متوسطة & 0.52- أقل من 0.68 & محايد & $3.39-2.60$ \\
\hline عالية & 0.68- أقل من 0.84 & موافق & $4.19-3.40$ \\
\hline عالية جداً & 0.84- أقل من 100 & موافق بشدة & $5-4.20$ \\
\hline
\end{tabular}

3. 3رض نتائج الدراسة:

عرض وتفسير التساؤل الأول الذى ينص على " ما هي الصعوبات الإدارية ( القيادية) التي تواجه تطبيق نظام جودة

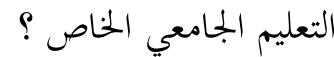

يتضح من الجدول السابق أن المتوسطات المرجحة للعبارات تراوحت ما بين (2.85- 3.67)، وكانت الأهمية للفقرتين (3، 4)، وهى عدم حرص الوزارة على توثيق سياسة تطبيق نظام الجودة ،وعدم حرص الوزارة على الإعلان عن سياسة تطبيق نظام الجودة ، حيث أجاب عليهما ما نسبته (33\%، 30\%) من أفراد العينة بموافق بشدة، وقد بلغ المتوسط الحسابي المرجح لمما على التوالي: (3.57، 3.05)، وبانحراف معياري (1.39، 160) بينما جاءت الأهمية النسبية للفقرات ذات الأرقام (1، 5، 6، 7) بموافق، وكانت أوزاها المئوية تتراوح ما بين (0.68- 0.84) ، وتعتبر هذه الأوزان عالية، وكانت فقرة واحدة وهى الفقرة الثانية أهميتها النسبية بغير موافق: 
عدد خاص بالورقات العلمية المقدمة للمؤتم الدولي الثاني للتعليم في ليبيا، مصراتة، ليبيا، مارس 2019

جدول (2) يبين المتوسط المرجح لفقرات البعد الأول، والاخرافات المعيارية، والأهمية النسبية.

\begin{tabular}{|c|c|c|c|c|c|c|c|c|c|}
\hline المستوى & المعياري & المتوجط & غوافق & غير & محايد & موافق & بشدة - موافق & العبارة & e \\
\hline موافق & 1.248 & 3.67 & 3 & 7 & 0 & 20 & 10 & 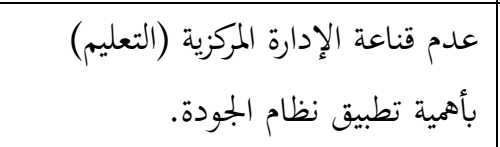 & 1 \\
\hline غير & 1.406 & 2.85 & 8 & 12 & 4 & 10 & 6 & عدم وضوح سياسة تطبيق نظام الجودة & 2 \\
\hline 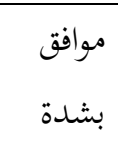 & 1.393 & 3.57 & 5 & 5 & 5 & 12 & 13 & 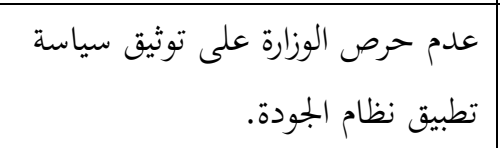 & 3 \\
\hline 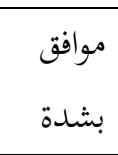 & 1.60 & 3.05 & 9 & 10 & 0 & 9 & 12 & سياسة تطبيق نظام الجودة. & 4 \\
\hline موافق & 1.34 & 3.22 & 4 & 13 & 0 & 16 & 7 & عدم حرص الوزارة على إشراك & 5 \\
\hline موافق & 1.40 & 3.22 & 7 & 6 & 6 & 13 & 8 & عدم حرص الوزارة على التواصل & 6 \\
\hline موافق & 1.38 & 3.02 & 6 & 9 & 8 & 10 & 7 & 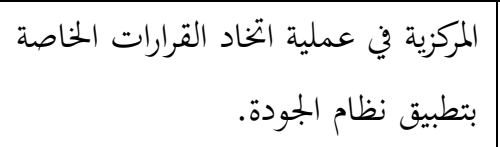 & 7 \\
\hline
\end{tabular}

البعد الثاني: الجانب الإداري والتنظيمي على المستوى المحلى (على مستوى المؤسسة)

أ. البعد الخاص بالتخطيط:

جدول (3) يبين المتوسط المرجح لفقرات بعد التخطيط، والانحرافات المعيارية، والأهمية النسبية.

\begin{tabular}{|c|c|c|c|c|c|c|c|c|c|}
\hline 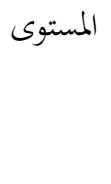 & الالمعراف & المرجح & غوافير & غوافر & 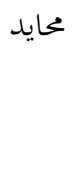 & موافق & مشوافق & 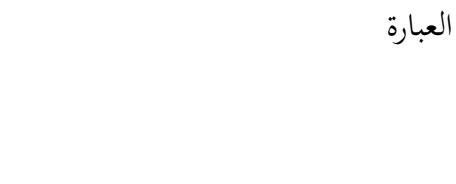 & s \\
\hline 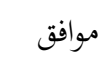 & 1.52 & 3.30 & 8 & 7 & 0 & 15 & 10 & عدم وضوح الأهداف & 1 \\
\hline 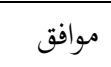 & 1.59 & 3.90 & 7 & 6 & 4 & 14 & 9 & عدم قابلية الأهداف للقياس & 2 \\
\hline 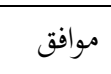 & 1.28 & 2.95 & 3 & 15 & 0 & 17 & 5 & عدم قابلية الأهداف للتحقيق & 3 \\
\hline 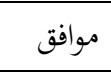 & 1.38 & 3.20 & 5 & 8 & 0 & 20 & 7 & عدم واقعية الأهداف & 4 \\
\hline موافق & 1.29 & 3.75 & 5 & 5 & 0 & 18 & 12 & عدم ارتباط الأهداف بغترة زمنية محددة & 5 \\
\hline موافق & 1.26 & 3.32 & 5 & 6 & 5 & 16 & 8 & الحططة المعتمدة للتنفيذ غير ملائمة & 6 \\
\hline
\end{tabular}


صعوبات تطبيق ضمان جودة التعليم الجامعي الخاص

مجلة كلية الآداب- العدد خاص (2) البجلد (1)

عدد خاص بالورقات العلمية المقدمة للمؤتمر الدولي الثاني للتعليم في ليبيا، مصراتة، ليبيا، مارس 2019

\begin{tabular}{|l|l|l|l|l|l|l|l|r|r|}
\hline & & & & & & & & & \\
\hline
\end{tabular}

يتضح من الجدول السابق أن جميع فقرات البعد المتعلقة بالتخطيط كانت في مستوى واحد حيث كانت أعلى الإجابات على جميع الفقرات بموافق ، وتراوحت المتوسطات المرجحة للفقرات ما بين (3.20- 3.90)، وبالنظر إلى الجدول (1) يتضح أن درجة الموافقة كانت تتراوح بين متوسطة وعالية، فالفقرات ذات الأرقام (1، 3، 4، 6) كانت درجة الموافقة متوسطة، أي أن وزها المئوي تراوح ما بين (0.52- 0.68)، بينما الفقرات ذات الأرقام (2، 5، 7) كانت درجة الموافقة عليها عالية، وتراوحت أوزاها المئوية ما بين (0.68- 0.84).

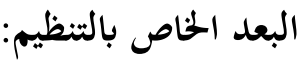

جدول (4) يبين المتوسط المرجح لفقرات بعد التخطيط، والانحرافات المعيارية، والأهمية النسبية.

\begin{tabular}{|c|c|c|c|c|c|c|c|c|c|}
\hline المستوى & المعياري & المرجح & موافق & غوافق & محايد & موافق & مشافق & العبارة & r \\
\hline موافق & 1.30 & 3.07 & 6 & 10 & 3 & 15 & 6 & واضحة تماماً. & 1 \\
\hline موافق & 1.37 & 3.52 & 4 & 9 & & 16 & 11 & بشكل واجبات أعضاء (منسقي) الأقسام & 2 \\
\hline مبدة & 1.40 & 3.75 & 4 & 7 & & 13 & 16 & 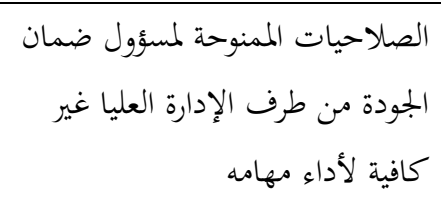 & 3 \\
\hline غوافق & 1.41 & 2.82 & 7 & 16 & & 11 & 6 & صدمن إدماج وحدة ضمان الجيكل التنظيمي للمؤسسة & 4 \\
\hline غوافق & 1.38 & 2.85 & 7 & 16 & & 11 & 6 & سواء علحداث حرص الإدارة العليا على محدات لضمان الجودة & 5 \\
\hline مبدة & 1.152 & 3.82 & & 10 & & 17 & 13 & علتطبيق نظام الجوادة الكوادر البشرية المؤهلة & 6 \\
\hline موافق & .812 & 4.17 & & 3 & 4 & 18 & 15 & 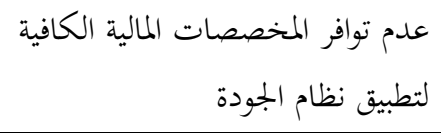 & 7 \\
\hline موافق & 1.037 & 4.00 & & 7 & & 19 & 14 & على الالتزام بالمعايير المعتمدة في الإدارة العليا للمؤسسة & 8 \\
\hline
\end{tabular}


صعوبات تطبيق ضمان جودة التعليم الجحامعي الخاص

مجلة كلية الآداب- العدد خاص (2) البجلد (1)

عدد خاص بالورقات العلمية المقدمة للمؤتمر الدولي الثاني للتعليم في ليبيا، مصراتة، ليبيا، مارس 2019

\begin{tabular}{|l|l|l|l|l|l|l|l|l|}
\hline & & & & & & & & \\
\hline \\
\hline
\end{tabular}

يتضح من الجدول السابق أن الفقرات ذات الأرقام (3، 6، 9) قد نالت الموافقة بشدة من أفراد العينة بدرجة أكبر من

البدائل الأخرى، وبلغت المتوسطات المرجحة على التوالي: (3.75، 3.82، 62.62)، وكان الوزن المئوي للفقرتين (3،

6) يتراوح ما بين (0.68- 0.84)، حيث درجة الموافقة كانت عالية، بينما جاء الوزن المئوي للفقرة (9) من (0.84- 100)، بدرجة موافقة عالية جداً، أما الفقرات ذات الأرقام (1، 2، 7، 8) فكانت أعلى إجابة لأفراد العينة بالموافقة، وبلغت المتوسطات المرجحة على التوالي: ( 3.07، 3.52، 4.17، 4.00)، وتتراوح الأوزان المئوية للفقرتين الأولى والثانية ما بين (0.52- 0.68)، وهى بدرجة موافقة متوسطة، بينما الفقرتان السابعة والثامنة بدرجة موافقه عالية جداً، وجاءت أعلى إجابات لأفراد العينة على الفقرتين (4، 5) بعدم الموافقة، وبلغت المتوسطات الحسابية لمما على التوالي: (2.82، 2.85). ج. البعد الخاص بالنوجيه: جدول (5) يبين المتوسط المرجح لفقرات بعد التوجيه، والانحرافات المعيارية، والأهمية النسبية.

\begin{tabular}{|c|c|c|c|c|c|c|c|c|c|}
\hline المستوى & المعياري & المتوسط & غوافق & غوافق & محايد & موافق & مشوافق & العبارة & p \\
\hline محايد & 1.210 & 2.85 & 6 & 9 & 16 & 5 & 4 & تطبط القيادة السائد في المؤسسة يعيق & 1 \\
\hline موافق & 1.30 & 3.50 & 3 & 10 & - & 18 & 9 & 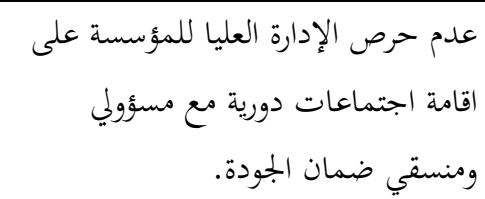 & 2 \\
\hline 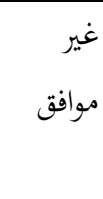 & 1.55 & 3.05 & 8 & 12 & - & 10 & 10 & عدام إقامة اجتماعات دورية مسؤل ضمان الجودة على أعضاء وحدته & 3 \\
\hline موافق & 1.26 & 3.30 & 5 & 6 & 7 & 16 & 6 & 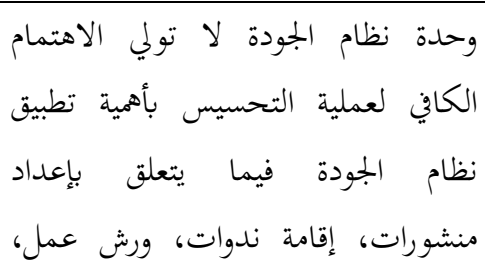 & 4 \\
\hline
\end{tabular}


صعوبات تطبيق ضمان جودة التعليم الجحامعي الخاص

مجلة كلية الآداب- العدد خاص (2) البجلد (1)

عدد خاص بالورقات العلمية المقدمة للمؤتم الدولي الثاني للتعليم في ليبيا، مصراتة، ليبيا، مارس 2019

\begin{tabular}{|c|c|c|c|c|c|c|c|c|c|}
\hline & & & & & & & & ملتقيات، لقاءات علمية & \\
\hline موافق & 1.00 & 3.60 & & 7 & 10 & 15 & 8 & الجمودة لا تتم وفق أسساذ القرارات الخاصة بتطبيق نظام & 5 \\
\hline محايد & .782 & 2.45 & & 5 & 25 & - & - & 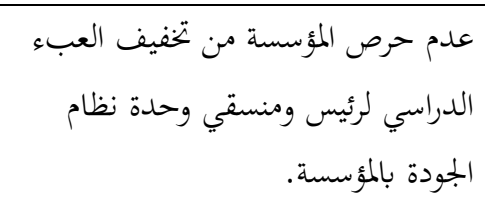 & 6 \\
\hline مشوافق & 1.18 & 4.02 & & 9 & & 12 & 19 & قلة البرامج التدريبية لمنسقي الجودة & 7 \\
\hline غوافق & 1.23 & 2.57 & 4 & 25 & - & 6 & 5 & 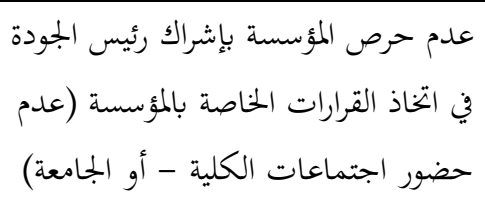 & 8 \\
\hline
\end{tabular}

يتضح من الجدول السابق أن الفقرات ذات الأرقام (2، 4، 5) أجاب أفراد العينة عليها بالموافقة بنسبة أكبر من البدائل الأخرى، وقد بلغت المتوسطات الحسابية المرجحة لمذه الفقرات الثلاث: (3.50، 3.30، 3.60)، وكانت عند وزن مئوي يتراوح ما بين (0.52- 0.68)، و بأهمية متوسطة، أما الفقرتان (1، 6) فكانت إجابات العينة عليهما أكبر من البدائل الأخرى، وقد بلغت المتوسطات الحسابية لمما على التوالي: (2.85، 2.45)، وبوزن مئوي يتراوح ما بين (0.52- 0.68) ، وبدرجة أهمية متوسطة، بينما أجاب أفراد العينة على الفقرتين (3، 8) بعدم الموافقة، أما الفقرة السابعة فقد أجاب عليها (48\%) من أفراد العينة بالموافقة بشدة، وبلغ المتوسط المرجح لها (4.02) ، وبوزن مئوي يتراوح ما بين (0.68- 0.84)، و بأهمية عالية.

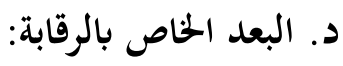

جدول (6) يبين المتوسط المرجح لفقرات بعد الرقابة، والانحرافات المعيارية، والأهمية النسبية.

\begin{tabular}{|c|c|c|c|c|c|c|c|c|c|}
\hline 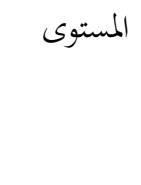 & المعياري & المرجح & غوافق & غوافق & 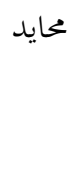 & موافق & موافق & 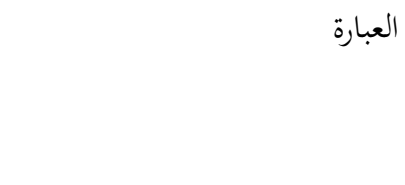 & s \\
\hline غير موافق & 1.13 & 3.00 & 2 & 17 & 8 & 7 & 6 & على على متابعة مدص الإدارة العليا للمؤسسة & 1 \\
\hline غير موافق & 1.32 & 2.80 & 7 & 14 & 6 & 7 & 6 & على الموضومة حتابعة التقدم الإدارة العليا للمؤسسة تنفيذ الخططة & 2 \\
\hline غير موافق & 1.27 & 2.40 & 11 & 16 & 4 & 5 & 4 & عدم حرص منسقي ضمان الجودة & 3 \\
\hline
\end{tabular}


عدد خاص بالورقات العلمية المقدمة للمؤتم الدولي الثاني للتعليم في ليبيا، مصراتة، ليبيا، مارس 2019

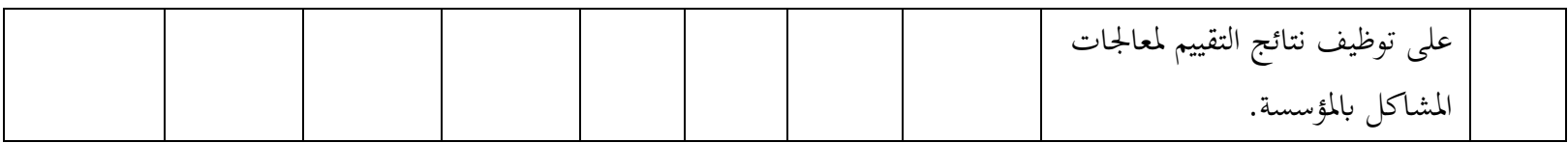

يتضح من الجدول السابق أن الفقرات الثلاثة المتعلقة بالرقابة أجابت عنها النسبة الكبيرة من أفراد العينة بعدم الموافقة، وبلغت المتوسطات الحسابية المرجحة لها على التوالي: (3.00، 2.80، 2.40)، حيث كانت الأهية للفقرة الأولى والثانية متوسطة، والفقرة الثالثة بدرجة ضعيفة.

\section{4. - 2 - تفسير نتائج الدراسة:}

1. ترى عينة الدراسة أن هناك صعوبات إدارية (قيادية) تواجه تطبيق نظام جودة التعليم الجامعي الخاص، وهذه الصعوبات تتمثل في عدم قناعة الإدارة العليا بأهمية تطبيق نظام الجودة، ، وعدم حرص الوزارة على توثيق نظام الجودة، وعدم التواصل المستمر مع مسؤولي نظام الجودة، والمركزية في عميلة اتخاذ القرار. وتتفق هذه النتيجة مع النتائج التي توصلت إليها رقاد؛ والعكيكيزة (2016)، والتي أشارت إلى وجود معوقات تحد من عملية تطبيق نظام الجودة، تتعلق بالجانب القيادي الوزاري، وأن أكثر المعوقات التي تشكل أهمية هي عدم الحرص على تطبيق نظام الجودة.

ويعلل الباحثان هذا القصور من الوزارة بتحه تطبيق نظام الجودة في التعليم الجامعي الخناص بعدم قناعة المسؤولين بالوزارة بأهمية التعليم الخاص من الأساس باعتباره رافدا للتعليم العام، فضلاً عن أن التعليم الخاص هو تعليم غير ممول من خزينة الدولة العامة (ميزانية التعليم)، وبالتالي فهو لا يشكل أهمية كبرى للوزارة؛ لأنه لا يندرج تحت خططها، إضافة إلى أن اعتماد سوق العمل اللبيي على مخرجات التعليم الجامعي العام أكثر من غيره دفع بالمسؤولين عليه إلى التركيز على ضمان جودته وإيجاد الحلول لمشاكله، وهذا بدوره جاء على حساب التعليم الجامعي الخاص. 2. ترى عينة الدراسة أن هناك قصوراً مؤسساتياً يتعلق بجانب التخطيط، من حيث عدم وضوح الأهداف، وقابليتها للقياس، وعدم قابلية الأهداف للتحقيق، وعدم واقعيتها، وعدم ارتباطها بفترة زمنية محددة. وهذا القصور من وجهة نظر الباحتَيْنِ يعود إلى حداثة تجربة التعليم الجامعي الخناص، فهو حديث النشأة مقارنة بالتعليم الجامعي الخاص في الدول العربية، والغربية ، ويشير (بدران؛ والدهشان، 2001: 166) إلى أن أول جامعة أهلية في مصر تم تأسيسها عام 1908. أيضاً عدم وجود المتخصصين في مجال التخطيط؛ الأمر الذى انعكس سلبا على نتائج هذا المحور، حيث كانت الإجابات السائدة لعينة الدراسة بموافق. 
عدد خاص بالورقات العلمية المقدمة للمؤتم الدولي الثاني للتعليم في ليبيا، مصراتة، ليبيا، مارس 2019

3. يشير مسؤولو ومنسقو ضمان الجودة بالجامعات الخاصة عينة الدراسة إلى أن هناك قصوراً واصحاً في بعض جوانب التنظيم كبعد إداري مؤسساتي، يتمثل في واجبات مسؤول ضمان الجودة، فهي غير واضحة تماماً، كما أن واجبات أعضاء (منسقي) الأقسام العلمية بوحدة نظام الجودة غير محددة بشكل واضح، وكذلك الصلاحيات الممنوحة لمسؤول ضمان الجودة من طرف الإدارة العليا غير كافية لأداء مهامه، وعدم توافر الكوادر البشرية المؤهلة لتطبيق نظام الجودة، وعدم حرص الإدارة العليا للمؤسسة على الالتزام بالمعايير المعتمدة في اختيار مسؤولي وحدة نظام الجودة، وعدم استقرار منسقي وحدة ضمان الجودة بالأقسام- الكلية- الجامعة. ويعقب الباحثان على هذه النتيجة بالآتي: أ. يفتقد أغلب منسقي الجودة بالأقسام بالجامعات الخاصة إلى التدريب الكافي في مجال الجودة. ب. التخبط العشوائي للإدارة في ليبيا، والمتمثل في عدم الاستقرار الإداري، أي عدم إعطاء الفرصة للقائمين على الجودة

$$
\text { للعمل فترة زمنية طويلة تمكنهم من اكتساب الحبرة في مجال ضمان الجودة. }
$$

د. خضوع القائمين على العملية التعليمية، بما فيهم منسقو ورؤساء ضمان الجودة، لسلطة الممولين للجامعة الخاصة. 4. يشير مسؤولو ومنسقو ضمان الجودة بالجامعات الخاصة، عينة الدراسة، إلى أن هناك قصوراً واصحاً في بعض جوانب التوجيه كبعد إداري مؤسساتي، يتمثل في عدم حرص الإدارة العليا للمؤسسة على إقامة اجتماعات دورية مع مسؤولي ومنسقي الجودة بالجامعة، وأن عملية اتخاذ القرار لا تتم وفق أسس علمية، فضلا عن ندرة البرامج التدريبية لمنسقي الجودة. ويعزى ذلك إلى تركيز القائمين على الجامعات الخاصة وخصوصاً المستثمرين في بجال التعليم على الجانب المادي والربحي أكثر من التركيز على النواحي التعليمية والأكاديمية، الأمر الذى يؤدى إلى اتخاذ قرارات إدارية فردية في بعض الأحيان لا تحقق أهداف المؤسسة التعليمية، ولا رسالتها.

5. يشير مسؤولو ومنسقو ضمان الجودة بالجامعات الخاصة عينة الدراسة إلى وجود رقابة متمثلة في حرص الإدارة العليا للمؤسسة على متابعة مدى التقدم في تحقيق نظام ضمان الجودة، والحرص على متابعة التقدم في تنفيذ الخطة الموضوعة، وحرص منسقي ضمان الجودة على توظيف نتائج التقييم لمعالجات المشاكل بالمؤسسة. وعلى الرغم من أن عينة الدراسة ترى وجود الجانب الرقابي فإن الباحثين، بحكم تعاوغما مع بعض الجامعات الخناصة، يبديان اختلافهما مع عينة الدراسة، وذلك لأن واقع العمل في الجامعات الخاصة وهياكلها الإدارية لا تتضمن الجانب الرقابي أو التفتيشي بصورة واضحة. 
1 .وضع ضمان الجودة بالجامعات الخاصة على قائمة أولويات الدولة.

2. التعاون بين الجامعات الحكومية والجامعات الخاصة لتبادل الأفكار والخبرات بما يحقق أهداف ضمان الجودة. 3. الاهتمام بتدريب منسقي ورؤساء مكاتب ضمان الجودة للرقى بالمؤسسة الجامعية. 4. الاهتمام بالبرامج التدريبية التي تركز على تطبيق ضمان الجودة بالجامعات الخاصة. البحوث المقترحة: 1. إجراء دراسة مماثلة على عينات أكبر من منسقي ورؤساء الإدارات لضمان الجودة. 2. دراسة مقارنة حول الصعوبات التي تواجه تطبيق نظام الجودة بين الجامعات الخاصة والجامعات الحكومية.

\section{قائمة المراجع}

\section{المراجع العربية: - م}

بدر، سالم عيسى؛ عباينة، عماد غضاب (2007): مبادىء الإحصاء الوصفي والاستدلالي، دار المسيرة، عمان، الأردن.

بدران، شبل؛ الدهشان، جمال (2001): التجديد في التعليم الجامعي، دار قباء، القاهرة. بن حسين، سمير (2015): تقييم فعالية خلايا ضمان الجودة في المساهمة في بناء وتطوير نظام ضمان جودة التعليم العالي في الجزائر، بجلة العلوم الاجتماعية والإنسانية، ع (18)، ص ص. 207- 220. الرفاعي، خليل؛ وآخرون (2012): تحديد معوقات تطبيق غدارة الجودة الشاملة في أقسام المحاسبة في الجامعات الحكومية الأردنية، المؤتمر العربي الدولي الثاني لضمان جودة التعليم العالي، 4-5 أبريل 2012، الجامعة الخليجية، البحرين.

رقاد، صليحة (2014): تطبيق نظام ضمان الجودة في مؤسسات التعليم العالي الجزائرية: آفاقه ومعوقاته، دراسة ميدانية بمؤسسات التعليم العالي للشرق الجزائري، رسالة دكتوراه غير منشورة، جامعة سطيف، كلية العلوم الاقتصادية والتجارية وعلوم التسيير. رقاد، صليحة؛ ولعكيكيزة، ياسين (2016): معوقات تطبيق ضمان الجودة في مؤسسات التعليم العالي الجزائرية (دراسة حالة الجامعات العمومية الجزائرية)، المجلة الجزائرية للدراسات المحاسبية والمالية، ع (3)، ص ص. 107- 
عدد خاص بالورقات العلمية المقدمة للمؤتم الدولي الثاني للتعليم في ليبيا، مصراتة، ليبيا، مارس 2019

- - السرحان، عطا الله بن فهد (2012): أثر تطبيق معايير الجودة والاعتماد الأكاديمي على تسويق مخرجات التعليم في الجامعات السعودية، المؤتمر العربي الدولي الثاني لضمان جودة التعليم العالي، 4-5 أبريل 2012، الجامعة الخليجية، البحرين.

السعدى، محمد زين صالح؛ وآخرون (2017): مدى تطبيق معايير ضمان الجودة والاعتماد الأكاديمي في جامعة الأندلس، مجلة الأندلس للعلوم الإنسانية والاجتماعية، م(16)، ع (15)، يوليو - سبتمبر، جامعة الأندلس للعلوم التقنية.

صبري، هالة عبد القادر (2009):جودة التعليم العالي ومايير الاعتماد الأكاديمي " تجربة التعليم الجامعي الخاص في الأردن"، المجلة العربية لضمان جودة التعليم الجامعي، ع (4)، ص. ص. 148- 176. الفرأ، وليد عبد الرحمن (2008): تحليل بيانات الاستبيان باستخدام البرنامج الإحصائي SPSS ، الندوة العلمية العالمية للشباب الإسلامي. قدومي، عبدالرحيم (2005): التعرف على مدى تطبيق ركائز ضمان الجودة في الأقسام الأكاديمية لكليات المال والأعمال، المجلة العربية لضمان جودة التعليم الجامعي، م (1)، ع (1)، ص ص. 47- 68). محمد، بلبية؛ وبندى، عبد السلام عبد الله (2016): تحديد معايير ضمان الجودة وتأثيرها على الاعتماد الأكاديمي بمؤسسات التعليم العالي - دراسة حالة كلية العلوم الاقتصادية والتجارية وعلوم التسيير، رسالة دكتوراه، غير منشورة، جامعة أبوبكر بلقايد، تلمسان، الجزائر. المنظمة الليبية للسياسات والاستراتيجيات ( 2013)، تقرير عن واقع التعليم العالي في ليبيا . النقري، إميليا محمود؛ والطروانة، إخليف يوسف (2018): درجة تحقيق الجامعات الأردنية لمعايير ضمان الجودة من وجهة نظر عمداء الكليات ورؤساء الأقسام الأكاديمية فيها، مجلة دراسات العلوم التربوية، م (45)، ع(3)، ص ص. يجياوي، نعيمة؛ وآخرون (2012): ضمان جودة التعليم الإلكتروني في مؤسسات التعليم العالي، المؤتمر العربي الدولي الثاني لضمان جودة التعليم العالي، الجامعة الخليجية، البحرين.

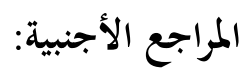

-Hoy, C., Bayne-Jardine, C., \& Wood, M. (2000). Improving quality in education. London: Falmer Press

-Adams, D. (1993). Defining educational quality. Improving Educational Quality Project Publication, 1 
-Delors et al. (1996): Learning: the Treasure Within. Report to UNESCO of the International Commission on Education for the Twenty-first Century. Paris: UNESCO

-Ulf Fredriksson (2004): Quality Education: The Key Role of Teachers , Education International Working Papers no. 14 September 2004.

-Jain and N. Prasad,(2018): Quality of Secondary Education in India, Springer Nature Singapore

$$
\text { مر اجع شبكة المعلومات الدولية: }
$$

https://mawdoo3.com/\%D8\% تعريف الجودة في التعليم 